[15] Bellman, R. E. and Zadeh, L. A. (1970), Decision making in a fuzzy environment, Management Sceince, 17(4), B141-B164.

[16] Tanaka, H., Okuda, T. and Asai, K. (1974), On fuzzy mathematical programming, Journal of Cybernetics, 3(4), 37-46.

[17] Zimmermann, H. J. (1976), Description and optimization of fuzzy systems, International Journal of General Systems , 2(4), 209-215.

[18] Roy, T. and Maiti, M. (1998), Multi-objective inventory models of deteriorating items with some constraints in a fuzzy environment, Computers and Operations Research, 25, 1085-1095.

[19] Zimmermann, H. J. (1978), Fuzzy linear programming with several objective functions, Fuzzy Sets and Systems, 1, 46-55.

\title{
ANNOUNCEMENT
}

2nd. International Conference on

Computing, Communication and Control Technologies: CCCT '04

August 14 - 17 - Austin, Texas, USA

Sponsored by: The University of Texas at Austin and IIIS: The International Institute of Informatics and Systemics

Conference Areas, Sub-areas and Topics

A. Computing and Information Systems and Technologies

B.Communication Systems, Technologies And Applications

C.Control Systems, Technologies And Applications

D. Hybrid Systems, Dual Technologies, Cross-Fertilizing Research and

Analogical Thinking

D. 1. Communications and Control

D. 2. Computing and Communications

D. 3. Computing and Control

D. 4. Computing, Communication and Control

E. Applications of CCCT in other areas

F. Applications of other areas in CCCT

G.Hybrid Applications

\section{Conference Contact}

Answers to specific questions can also be requested by e-mail to the following addresses:

CCCT04@iiis.org or SEC.CCCT04@iiis.org

Complete details of CCCT ' 04 can be had on the Conference web-site at: http://www.iiisci.org/ccct2004/WebSite/Default.asp . 